\title{
Penjaringan Kriteria dalam Desain Ulang Instrumen Pengukuran Kepuasan Pelayanan Perusahaan Distribusi Minyak Milik Negara
}

\author{
Primahasmi Dalulia ${ }^{1^{\star}}$, Erwin Dwi Pambudi ${ }^{2}$, \\ 12Jurusan Teknik Industri ,Universitas Merdeka Malang \\ *Korespondensi Penulis, E-mail: primahasmi.dalulia@unmer.ac.id \\ Diterima : 22 April 2019 \\ Direvisi : 24 April 2019 \\ Disetujui : 29 April 2019
}

\begin{abstract}
Abstrak
Bahan Bakar Minyak berperan bagi sektor industri maupun transportasi. Sebagai distributor BBM area Malang dan sekitarnya, Terminal Bahan Bakar Minyak (TBBM) Malang harus memiliki strategi dalam melakukan kegiatan pelayanannya terhadap pelanggan (SPBU). Adanya rasa puas dari pelanggan merupakan harapan dari setiap perusahaan guna meningkatkan loyalitas dari pelanggan dan memenuhi harapan yang diinginkan oleh pelanggan. Penelitian ini bertujuan untuk mendesain ulang kuesioner kepuasan konsumen yang pernah dilakukan oleh TBBM Malang. Desain ulang kuesioner kepuasan konsumen dilakukan karena kuesioner terdahulu kurang relevan dengan harapan TBBM Malang. Perlunya kuesioner ini didesain ulang karena dalam kuesioner lama belum mengakomodasi perubahan sistem dan aspirasi konsumen. Kuesioner baru dibuat berdasar dari aspirasi dari konsumen mengenai faktor-faktor apa saja yang menjadi penilaian penting terkait dengan kualitas pelayanan pada TBBM Malang. Dari faktor - faktor tersebut dapat digunakan oleh TBBM Malang untuk melakukan evaluasi kepuasan pelanggan secara berkala. Perbaikan kuesioner ini bertujuan agar pertanyaan - pertanyaan dalam kuesioner lebih efektif untuk mengevaluasi kepuasan pelanggan. Penelitian ini dilakukan pada TBBM Malang dengan metode Delphi.. Hasil dari penelitian ini antara lain faktor yang mempengaruhi kepuasan pelanggan adalah Mobil tangki, awak mobil tangki, pengiriman BBM dan Pelayanan pada TBBM Malang.
\end{abstract}

Kata Kunci : Bahan Bakar Minyak, Delphi, Kuesioner, Kriteria, Pelayanan

\section{Pendahuluan}

Bahan bakar minyak (BBM) adalah kebutuhan pokok bagi masyarakat saat ini baik pada sektor rumah tangga maupun sebagai pengusaha. BBM juga sangat penting bagi sektor industri maupun transportasi. Kondisi ini dapat dilihat dari peranan BBM sebagai salah satu faktor penting dalam menentukan perubahan harga bahan pokok makanan atau inflasi. Melihat pentingnya peranan BBM dalam kehidupan masyarakat pemerintah pun akhirnya ikut campur tangan dalam penentuan harga dan menjamin ketersediaanya untuk masyarakat.

Menurut Parasuraman (1998) dalam [1] kualitas jasa dapat didefinisikan sebagai seberapa jauh perbedaan antara kenyataan dan harapan pelanggan atas layanan yang mereka terima. Berdasarkan uraian, dapat disimpulkan bahwa kualitas jasa suatu titik fokus yang diupayakan dalam suatu produk atau pelayanan untuk dapat memenuhi keinginan dan kepuasan pelanggan dalam memenuhi kebutuhannya [4]. Dalam hal ini yang dimaksud pelanggan adalah SPBU yang melakukan pembelian BBM pada TBBM MALANG. Wilayah suplai dari TBBM MALANG meliputi Kota Malang, Kabupaten Malang, Kota Batu, Blitar, Tulungagung, Lumajang yang berjumlah 89 SPBU,1 SPDN dan 2 TNI/POLRI. Dalam hal ini TBBM MALANG harus memiliki strategi dalam melakukan kegiatan pelayanannya terhadap pelanggan (SPBU), adanya rasa puas dari pelanggan merupakan harapan dari setiap perusahaan guna meningkatkan loyalitas dari pelanggan dan memenuhi harapan yang diinginkan oleh pelanggan. 
Penelitian ini bertujuan untuk mendesain ulang kuesioner kepuasan konsumen yang pernah dilakukan oleh TBBM MALANG. Desain ulang kuesioner kepuasan konsumen dilakukan karena pertanyaan pada kuesioner terdahulu kurang relevan dengan harapan TBBM MALANG. Kurang relevan dalam hal ini adalah dari sisi waktu pembuatan kuesioner yang sudah terlalu lama yang terakhir perbaikannya dilakukan pada tahun 2015 sedangkan setiap tahun pada TBBM MALANG diadakan program pengembangan usulan pada masing-masing anak perusahaan, dalam hal ini TBBM MALANG berkeinginan untuk mengakomodasi aspirasi pelanggan. Alasan ini disampaikan oleh Supervisor Departemen Quality \& Quantity TBBM MALANG Malang. Selain itu perlunya kuesioner ini didesain ulang karena dalam kuesioner lama belum mengakomodasi perubahan sistem dan aspirasi konsumen belum terakomodasi. Maka dari itu akan dibuatlah penjaringan kriteria baru berdasar dari keinginan dari konsumen mengenai faktor-faktor apa saja yang menjadi penilaian penting terkait dengan kualitas pelayanan pada TBBM MALANG. Dari kriteria tersebut kemudian dapat digunakan oleh TBBM MALANG untuk melakukan perbaikan instrumen pengukuran kepuasan pelayanan. Perbaikan instrumen ini bertujuan agar pertanyaan - pertanyaan dalam instrumen yang berupa kuesioner lebih efektif untuk mengevaluasi kepuasan pelanggan terhadap kualitas pelayanan di TBBM MALANG Malang.

Terdapat banyak metode yang dikembangkan untuk penjaringan pendapat subjektif dalam lingkup manajemen. Porter et. al. (1980) dalam [2] membuat klasifikasi metodeloginya yang meliputi metode forecasting-jenius, metode survei atau polling, metode forecasting panel-interaktif dan metode Delphi, survei-umpan balik tanpa interaksi. Sementara Khorramshahgol dan Moustakis (1993) dalam [2] mengungkap metode lain seperti : metode Teori Utilitas dari Bernouli, model Ekonometrik dan "SocioPsychological Scalling Technique". Metode Delphi sendiri biasanya digunakan sebagai suatu metode penjaringan pendapat kelompok yang partisipannya terdiri dari narasumber atau expert yang memiliki keahlian dalam bidangnya. Pendekatan ini dapat dijadikan sarana saling menyampaikan informasi dalam memperoleh informasi yang mendalam bagaimana dinamika suatu pendapat dari setiap individu dalam suatu survei bisa berkembang dan kemudian memperoleh legitimasi menjadi pendapat kelompok (Doke dan Swanson, 1995) dalam [2]. Pendekatan Delphi dapat dipergunakan untuk proses pengambilan keputusan kelompok semacam "musyawarah mufakat tertulis" tanpa harus interaksi langsung antar pengambil keputusan, pakar atau anggota lainnya, kecuali dengan pemrasarananya. Rasionalisasi dari metode ini adalah "two (n) heads are better than one" (Linstone dan Turoff, 1975) dalam [2] . Metode Delphi dipandang lebih tepat dipergunakan untuk menjaring pendapat untuk perumusan visi maupun objektif disebabkan pertimbangan :

1. Kemampuannya untuk menampung pendapat subjektif setiap individu secara iteratif dan adanya feedback terkendali dalam penilaian respon kelompok

2. Sifat anonim dalam penjaringan survei, maka memungkinkan responden mengungkapkan pendapat secara bebas dan tak memunculkan efek dominasi atau pengaruh sesuatu pendapat dari seseorang yang memiliki otoritas lebih tinggi dalam melahirkan ide.

3. Semua responden terlibat secara aktif sejak pertama proses dan putaran survei sehingga mempermudah dalam mencari solusi yang berkompromi serta memberikan efektivitas tinggi dalam implementasi keputusan.

Karenanya hasil dari survei metode Delphi berupa pendapat individu yang subjektif maka masih diperlukan suatu pendekatan lain untuk menstrukturkannya menjadi pendapat kelompok sehingga lebih objektif dan dapat diuji konsistensinya [3]. 


\section{METODE}

Secara garis besar penentuan kriteria baru dalam penelitian ini menggunakan metode Delphi yang kemudian dilakukan proses elaborasi kriteria-kriteria yang memiliki inti pengertian sama [3].

\subsection{Tahap Penentuan Kriteria Baru}

Pada penelitian ini, penentuan kriteria baru dilakukan dengan pendekatan Delphi. Menurut [2] kriteria diartikan sebagai tolok ukur atau ambang baku yang mengarahkan pemilihan alternatif pada pencapaian obyektif keputusan atau kebijakan yang telah ditetapkan. Metode Delphi umumnya digunakan untuk menjaring opini dimana di dalamnya terdapat partisipan-partisipan yang kompeten di bidangnya. Tahap awal dalam penjaringan kriteria adalah memberikan pertanyaan terbuka terkait kriteria yang belum terdapat pada kuesioner lama.

\subsection{Delphi Putaran Pertama}

Pada kuesioner Delphi putaran pertama responden dari kuesioner ini adalah para pengawas pada SPBU area suplai TBBM MALANG dengan pengisian kuesioner menggunakan aplikasi google form dan pengambilan data dilakukan selama 1 minggu mulai tanggal 1 sampai 6 Oktober 2018. Berikut merupakan hasil dari kuesioner Delphi putaran pertama :

Tabel 2.1 Tabel Hasil Delphi Putaran Pertama

\begin{tabular}{|l|l|c|}
\hline \multicolumn{1}{|c|}{ Kriteria } & \multicolumn{1}{|c|}{ Pengertian } & Responden \\
\hline \multicolumn{1}{|c|}{1} & \multicolumn{1}{|c|}{2} & \multicolumn{1}{|c|}{3} \\
\hline Keramahan & $\begin{array}{l}\text { Keramahan TBBM apabila ada trouble dari } \\
\text { pihak SPBU atau TBBM }\end{array}$ & Responden 1 \\
Awak Mobil & $\begin{array}{l}\text { Keramahan dan pelayanan awak mobil tangki } \\
\text { Tangki (AMT) }\end{array}$ & $\begin{array}{l}\text { Raat pesponden 1 } \\
\text { kesalahan diperlukan agar bisa bekerjasama }\end{array}$ \\
\hline Loses & $\begin{array}{l}\text { Jumlah kehilangan BBM/BBK yang melebihi } \\
\text { batas wajar dalam perjalanan pada proses } \\
\text { distribusi dari TBBM ke SPBU }\end{array}$ & Responden 1 \\
\hline $\begin{array}{l}\text { Ritase } \\
\text { Pengiriman }\end{array}$ & $\begin{array}{l}\text { Ketepatan waktu pengiriman disesuaikan } \\
\text { dengan permintaan konsumen }\end{array}$ & Responden 2 \\
\hline $\begin{array}{l}\text { Pengirim } \\
\text { sesuai jadwal }\end{array}$ & $\begin{array}{l}\text { Pengiriman BBM terkadang tidak sesuai jadwal } \\
\text { permintaan ritase }\end{array}$ & Responden 3 \\
\hline $\begin{array}{l}\text { Ritase } \\
\text { Pengiriman }\end{array}$ & $\begin{array}{l}\text { Waktu disesuaikan dengan permintaan } \\
\text { konsumen }\end{array}$ & Responden 4 \\
\hline $\begin{array}{l}\text { Masalah } \\
\text { Pengiriman } \\
\text { tidak sesuai dengan sms konfirmasi pesanan }\end{array}$ & Responden 5 \\
\hline
\end{tabular}




\begin{tabular}{|c|c|c|}
\hline $\begin{array}{l}\text { Pengawasan } \\
\text { perjalanan } \\
\text { AMT }\end{array}$ & $\begin{array}{c}\text { Perjalanan AMT dari TBBM ke SPBU } \\
\text { lebih diawasi agar tidak terjadi loses yang } \\
\text { melebihi batas toleransi }\end{array}$ & Responden 6 \\
\hline $\begin{array}{l}\text { Pengiriman } \\
\text { tepat waktu }\end{array}$ & $\begin{array}{l}\text { Untuk stock produk yang sudah habis kiranya } \\
\text { bisa diprioritaskan untuk ketersediaan BBK } \\
\text { pada SPBU }\end{array}$ & Responden 7 \\
\hline AMT Telat & $\begin{array}{l}\text { AMT telat datang stock SPBU habis sehingga } \\
\text { berpengaruh pada penjualan }\end{array}$ & Responden 8 \\
\hline $\begin{array}{l}\text { Surat tera } \\
\text { mobil tangki }\end{array}$ & Surat tera tidak kadaluarsa & Responden 9 \\
\hline $\begin{array}{l}\text { Buku tera } \\
\text { mobil tangki }\end{array}$ & Buku tera tangki asli/resmi dan masih berlaku & Responden10 \\
\hline $\begin{array}{lr}\text { Variasi } & \text { mobil } \\
\text { tangki } & \text { dan } \\
\text { awak } & \text { mobil } \\
\text { tangki } & \end{array}$ & $\begin{array}{l}\text { Pengiriman BBM/BBK menggunakan mobil } \\
\text { tangki dan awak mobil tangki yang bervariasi }\end{array}$ & Responden 11 \\
\hline Mobil tangki & $\begin{array}{l}\text { Ukuran T1 dan T2 sesuai dengan exjbout dan } \\
\text { buku tera }\end{array}$ & Responden 12 \\
\hline $\begin{array}{l}\text { Awak mobil } \\
\text { tangki }\end{array}$ & Menggunakan seragam dinas sesuai standard & Responden 13 \\
\hline $\begin{array}{l}\text { Surat tera } \\
\text { mobil tangki }\end{array}$ & Surat tera tidak kadaluarsa & Responden 14 \\
\hline Mobil tangki & Pembaruan mobil tangki yang sudah tua/lama & Responden 15 \\
\hline Mobil tangki & $\begin{array}{l}\text { Surat tera mobil tangki dan identitas sopir } \\
\text { asli(bukan sopir pengganti) sesuai dengan } \\
\text { informasi yang diberikan kepada SPBU }\end{array}$ & Responden 16 \\
\hline
\end{tabular}


Lanjutan Tabel 2.1 Hasil Delphi Putaran Pertama

\begin{tabular}{|l|l|l|}
\hline \multicolumn{1}{|c|}{1} & \multicolumn{1}{|c|}{2} & 3 \\
\hline $\begin{array}{l}\text { Waktu } \\
\text { pengiriman }\end{array}$ & $\begin{array}{l}\text { Pengiriman disesuaikan dengan waktu yang } \\
\text { diminta oleh SPBU }\end{array}$ & Responden 17 \\
\hline Mobil tangki & Kondisi penampilan mobil tangki & Responden 18 \\
\hline Mobil tangki & $\begin{array}{l}\text { Penutup tangki atas (mainhold) engsel } \\
\text { dibuatkan segel }\end{array}$ & Responden 19 \\
\hline $\begin{array}{l}\text { Awak mobil } \\
\text { tanki }\end{array}$ & Penampilan awak mobil tangki & Responden 20 \\
\hline Mobil tangki & Peremajaan mobil tangki yang sudah tua & Responden 21 \\
\hline
\end{tabular}

\subsection{Tahap Elaborasi}

Tahap elaborasi merupakan tahap dimana mencari faktor-faktor atau kriteria yang memiliki pengertian sama untuk dijadikan menjadi satu faktor atau kriteria saja sehingga lebih ringkas dan lebih mudah untuk dipahami. Hasil elaborasi kriteria pada Delphi putaran pertama disajikan pada tabel 2.2

Tabel 2.2 Tabel Elaborasi Hasil Delphi Putaran Pertama

\begin{tabular}{|c|l|l|}
\hline No. & \multicolumn{1}{|c|}{ Kriteria } & \multicolumn{1}{|c|}{ Pengertian } \\
\hline 1 & \multicolumn{1}{|c|}{3} \\
\hline 1 & Keramahan & $\begin{array}{l}\text { Keramahan TBBM apabila } \\
\text { ada trouble terjadi pada pihak } \\
\text { SPBU atau TBBM }\end{array}$ \\
\hline 2 & Pelayanan Awak Mobil Tangki & $\begin{array}{l}\text { Keramahan dan pelayanan } \\
\text { Awak Mobil Tangki sangat } \\
\text { diperlukan agar bisa } \\
\text { bekerjasama saat } \\
\text { pembongkaran BBM dan } \\
\text { tidak terjadi kesalahan }\end{array}$ \\
\hline 3 & Loses & $\begin{array}{l}\text { Jumlah kehilangan BBM/BBK } \\
\text { yang melebihi batas wajar } \\
\text { dalam perjalanan pada } \\
\text { proses distribusi dari TBBM } \\
\text { ke SPBU }\end{array}$ \\
\hline
\end{tabular}




\begin{tabular}{|c|c|c|}
\hline 4 & Ketepatan waktu pengiriman & $\begin{array}{l}\text { Penjadwalan waktu } \\
\text { pengiriman produk ke SPBU } \\
\text { disesuaikan dengan } \\
\text { permintaan dari SPBU }\end{array}$ \\
\hline 5 & $\begin{array}{l}\text { Administrasi mobil tangki dan awak mobil } \\
\text { tangki }\end{array}$ & $\begin{array}{l}\text { Surat tera mobil tangki resmi } \\
\text { dan masih berlaku serta } \\
\text { identitas awak mobil tangki } \\
\text { sesuai dengan yang } \\
\text { diinformasikan,jika ada } \\
\text { pergantian awak mobil tanki } \\
\text { diinfokan kepada pihak } \\
\text { SPBU }\end{array}$ \\
\hline 6 & $\begin{array}{l}\text { Variasi mobil tangki dan awak mobil } \\
\text { tangki }\end{array}$ & $\begin{array}{l}\text { Variasi dari mobil tanki dan } \\
\text { dan awak mobil tanki yang } \\
\text { mengirim ke SPBU lebih } \\
\text { bervariasi }\end{array}$ \\
\hline 7 & Kondisi fisik Mobil tangki & $\begin{array}{l}\text { Peremajaan mobil tangki } \\
\text { yang sudah tua }\end{array}$ \\
\hline 8 & Takaran Mobil tangki & $\begin{array}{l}\text { Letak } \mathrm{T} 1 \text { dan } \mathrm{T} 2 \text { sesuai } \\
\text { dengan ijkbout dan buku tera } \\
\text { ( } \mathrm{T} 1=\text { ukuran ruang kosong } \\
\text { pada mobil tangki, } \mathrm{T} 2=\text { ukuran } \\
\text { volume pasti pada mobil } \\
\text { tangki) }\end{array}$ \\
\hline 9 & Keamanan Mobil tangki & $\begin{array}{l}\text { Penutup atas mobil tangki } \\
\text { (main hole) diberi segel untuk } \\
\text { memberi keamanan lebih } \\
\text { terhadap BBM/BBK yang } \\
\text { dikirim }\end{array}$ \\
\hline 10 & Atribut Awak mobil tangki & $\begin{array}{l}\text { Menggunakan seragam dan } \\
\text { atribut yang sesuai dengan } \\
\text { standard }\end{array}$ \\
\hline
\end{tabular}




\subsection{Delphi Putaran Kedua}

Pada kuesioner Delphi putaran kedua responden dari kuesioner ini adalah para pengawas pada SPBU area suplai TBBM Malang dan pengambilan data dilakukan selama 3 hari mulai tanggal 7 sampai 9 Januari 2019 dengan pengisian kuesionermenggunakan aplikasi Google Form. Dalam kuesioner Delphi putaran kedua ini pertanyaannya berasal dari pernyataan responden yang telah diproses dalam tahap elaborasi dan kemudian para responden diberikan tugas untuk memberikan nilai seberapa penting kriteria tersebut untuk dimasukkan dalam perbaikan kuesioner mendatang. Dari 21 responden pada Delphi putaran pertama diberikan kuesioner lanjutan Delphi putaran kedua. Hasil dari Delphi putaran kedua disajikan dalam tabel 2.3

Tabel 2.3. Tabel Hasil Penilaian Delphi Putaran Kedua

\begin{tabular}{|c|c|c|c|}
\hline No. & Kriteria & Pengertian & $\begin{array}{l}\text { Rata-rata } \\
\text { Penilaian }\end{array}$ \\
\hline 1 & 2 & 3 & 4 \\
\hline 1 & $\begin{array}{l}\text { Pelayanan TBBM } \\
\text { Malang }\end{array}$ & $\begin{array}{l}\text { Keramahan dalam mengatasi } \\
\text { masalah yang terjadi baik pada } \\
\text { TBBM atau SPBU }\end{array}$ & 8,1 \\
\hline 2 & $\begin{array}{l}\text { Pelayanan awak } \\
\text { mobil tangki (AMT) }\end{array}$ & $\begin{array}{l}\text { Pelayanan dan keramahan AMT } \\
\text { pada saat pembongkaran BBM } \\
\text { di SPBU }\end{array}$ & 8,10 \\
\hline 3 & Loses & $\begin{array}{l}\text { Transport loss yang melebihi } \\
\text { batas toleransi } 0,15 \%\end{array}$ & 8,05 \\
\hline 4 & $\begin{array}{l}\text { Ketepatan waktu } \\
\text { pengiriman BBM }\end{array}$ & $\begin{array}{l}\text { Kesesuaian waktu pengiriman } \\
\text { dengan ODi }\end{array}$ & 8,05 \\
\hline 5 & $\begin{array}{l}\text { Administrasi mobil } \\
\text { tangki (MT) dan } \\
\text { awak mobil tangki } \\
\text { (AMT) }\end{array}$ & $\begin{array}{l}\text { Surat tera MT yang masih } \\
\text { berlaku dan identitas } \\
\text { AMTsesuai dengan yang } \\
\text { diinformasikan pada pihak } \\
\text { SPBU }\end{array}$ & 8,86 \\
\hline 6 & $\begin{array}{l}\text { Variasi mobil tangki } \\
\text { (MT) dan awak mobil } \\
\text { tangki (AMT) }\end{array}$ & $\begin{array}{l}\text { Variasi MT dan AMT yang } \\
\text { mengirim pesanan BBM ke } \\
\text { SPBU }\end{array}$ & 8,10 \\
\hline 7 & $\begin{array}{l}\text { Kondisi mobil tangki } \\
\text { (MT) }\end{array}$ & $\begin{array}{l}\text { Peremajaan mobil tangki yang } \\
\text { sudah tua dan sering rusak }\end{array}$ & 8,24 \\
\hline 8 & $\begin{array}{l}\text { Takaran mobil tangki } \\
\text { (MT) }\end{array}$ & $\begin{array}{l}\text { Volume mobil tangki sesuai } \\
\text { antara ijkbout dan T2 nya }\end{array}$ & 8,43 \\
\hline
\end{tabular}


Lanjutan Tabel 2.3. Tabel Hasil Penilaian delphi Putaran Kedua

\begin{tabular}{|c|l|l|c|}
\hline 1 & \multicolumn{1}{|c|}{2} & \multicolumn{1}{|c|}{3} & 4 \\
\hline 9 & $\begin{array}{l}\text { Keamanan mobil } \\
\text { tangki }\end{array}$ & $\begin{array}{l}\text { Kondisi segel mainhole dan } \\
\text { mainfold selalu dalam kondisi } \\
\text { baik }\end{array}$ & 9,14 \\
\hline 10 & $\begin{array}{l}\text { Atribut awak mobil } \\
\text { tangki (AMT) }\end{array}$ & $\begin{array}{l}\text { Menggunakan seragam dan } \\
\text { atribut sesuai dengan standard }\end{array}$ & 7,81 \\
\hline
\end{tabular}

Dari data pada tabel 2.3 didapatkan nilai rata-rata penilaian untuk setiap kriteria sudah lebih dari 7,5 atau $75 \%$ dari forum. Nilai $75 \%$ ini sudah dianggap mewakili kuota forum. Jadi kriteria yang digunakan sebagai acuan tambahan perancangan ulang kuesioner kepuasan pelanggan ada 10 kriteria. Kendala yang dialami pada Delphi putaran kedua adalah terbatasnya waktu koordinasi antara pihak peneliti dengan pihak TBBM Malang.

\section{KESIMPULAN DAN SARAN}

Dari penelitian yang dilakukan didapat faktor yang mempengaruhi kepuasan pelanggan PT Pertamina (Persero) TBBM Malang adalah Mobil tangki, awak mobil tangki, pengiriman BBM dan Pelayanan pada TBBM Malang. Setelah dilakukan proses verifikasi dan validasi usulan kriteria baru tersebut valid dan relevan untuk diterapkan pada TBBM Malang dengan perubahan mengakomodasi kepentingan pelanggan dan adanya tingkat kepentingan berupa bobot.

\section{DAFTAR PUSTAKA}

[1] Lupiyoadi, R , 2014. Manajemen Pemasaran di Indonesia : Analisis, Perencanaan, Implementasi dan Pengadilan. Jakarta : Salemba empat.

[2] Ciptomulyono, U., 2001. Intregasi Metode Delphi Dan Prosedur Analisis Hierarkhis (AHP) Untuk Identifikasi Dan Penentuan Prioritas Kriteria Objektif/Kriteria Keputusan. Jurnal Pengetahuan Alam Dan Teknologi 12,(1).

[3] Dalulia, Primahasmi dan M.L. Singgih. 2015 Pengembangan Kriteria Pengukuran Performansi. Program Studi MMT-ITS.

[4] Tjiptono, Fandy (2014). Pemasaran Jasa. Yogyakarta. Penerbit ANDI. 